\title{
Regulation of SOX10 stability via ubiquitination-mediated degradation by Fbxw7 $\alpha$ modulates melanoma cell migration
}

\author{
Xiao-Bin Lv ${ }^{1,2, *}$, Wei Wu ${ }^{2,4, *}$, Xiaofeng Tang ${ }^{1, *}$, Yanqing Wu ${ }^{4}$, Yinghua Zhu ${ }^{2}$, Yujie \\ $\mathrm{Liu}^{2,4}$, Xiuying $\mathrm{Cu}^{2}$, Junjun $\mathrm{Ch}^{2,4}$, Pengnan $\mathrm{Hu}^{2,4}$, Jingjing $\mathrm{Li}^{2,4}$, Qiannan Guo ${ }^{2,4}$, \\ zeming $\mathrm{Cai}^{1}$, Juan Wu${ }^{5}$, Kaishun $\mathrm{Hu}^{2}$, Nengyong Ouyang ${ }^{2,3}$ \\ ${ }^{1}$ Nanchang Key Laboratory of Cancer Pathogenesis and Translational Research, the Third Affiliated Hospital, Nanchang \\ University, Nanchang, China \\ ${ }^{2}$ Guangdong Provincial Key Laboratory of Malignant Tumor Epigenetics and Gene Regulation, Medical Research Center, Sun \\ Yat-Sen Memorial Hospital, Sun Yat-Sen University, Guangzhou, China \\ ${ }^{3}$ Department of Obstetrics and Gynecology, Sun Yat-Sen Memorial Hospital, Sun Yat-Sen University, Guangzhou, China \\ ${ }^{4}$ Breast Tumor Center, Sun Yat-Sen Memorial Hospital, Sun Yat-Sen University, Guangzhou, China \\ ${ }^{5}$ Cancer Center of Guangzhou Medical University, Guangzhou, China \\ *These authors have contributed equally to this work
}

Correspondence to:

Xiao-Bin Lv, e-mail: promab2006@126.com

Nengyong Ouyang, e-mail: ouyangny@sina.com

Keywords: SOX10, Fbxw $7 \alpha$, ubiquitination, melanoma, GSK3 $\beta$

Received: April 27, $2015 \quad$ Accepted: September 29, 2015

Published: October 09, 2015

\section{ABSTRACT}

Dysregulation of SOX10 was reported to be correlated with the progression of multiple cancer types, including melanocytic tumors and tumors of the nervous system. However, the mechanisms by which SOX10 is dysregulated in these tumors are poorly understood. In this study, we report that SOX10 is a direct substrate of Fbxw7a E3 ubiquitin ligase, a tumor suppressor in multiple cancers. Fbxw7a promotes soX10 ubiquitination-mediated turnover through CPD domain of SOX10. Besides, GSK3 $\beta$ phosphorylates SOX10 at CPD domain and facilitates Fbxw7a-mediated SOX10 degradation. Moreover, SOX10 protein levels were inversely correlated with Fbxw7a in melanoma cells, and modulation of Fbxw7a levels regulated the expression of SOX10 and its downstream gene MIA. More importantly, SOX10 reversed Fbxw7a-mediated suppression of melanoma cell migration. This study provides evidence that the tumor suppressor Fbxw7a is the E3 ubiquitin ligase responsible for the degradation of SOX10, and suggests that reduced Fbxw7a might contribute to the upregulation of soX10 in melanoma cells.

\section{INTRODUCTION}

SRY-related HMG box-containing factor 10 (SOX10) is a transcription factor that belongs to the HMGbox transcription factor family; this protein is initially expressed in premigratory neural crest cells and controls the multipotency, survival, and proliferation of neural crest cells as well as their differentiation into peripheral glial cells and pigment cells at later stages [1]. In addition to its role as a multipotency factor in stem cells, SOX10 has been implicated in the expression of lineage-specific genes in glia and melanocytes [2-4]. Homozygous deletion of SOX10 in mice leads to embryonic lethality, whereas SOX10 haploinsufficiency results in a melanocytic phenotype with reduced pigmentation of the belly and limb extremities $[5,6]$. Previous studies have revealed low frequencies of intragenic mutations of the Sox 10 gene in metastatic melanoma, suggesting that SOX10 might be involved in mediating melanoma metastasis [7]. Upregulation of SOX10 protein has been observed in multiple cancer types, including melanocytic tumors and tumors of the nervous system. More recently, a critical role 
for SOX10 in tumorigenesis and melanoma migration has been demonstrated in cell lines and mouse models [8-11].

SOX10 expression is tightly regulated at the transcriptional level. Fourteen multiple-species conserved sequences (MCS) were reported to display high levels of evolutionary conservation and variable control of Sox 10 expression [12-14]. SOXE was identified as binding to MSC4 and MSC7 and thereby enhancing the expression of Sox10. Moreover, four transcriptional factors were found to directly activate Sox10 transcription [1, 13]. Autoregulation of Sox 10 has been shown in Schwannoma cells [3]. Recently, Sox10 expression was shown to be directly activated in immortalized mammary gland epithelial cells by the TRAP/Drip/Mediator complex, which includes Mediator complex subunit 1 (MED1) and activates gene transcription. MED1 is recruited to the Sox10 promoter at MCS4 and MCS7, and knockdown of MED1 expression completely ablates Sox 10 expression in this cell line [15]. The regulation of SOX10 protein at the posttranslational level is less well understood. One study suggested that sumoylation at K55, K246 and K357 of SOX10 by Ubc9 repressed the transcriptional activity of SOX10 [16]. However, the mechanism by which SOX10 protein stability is regulated remains unknown.

Fbxw7 is the substrate recognition component of the Skp1-Cul1-F-box (SCF) ubiquitin-ligase $\mathrm{SCF}^{\mathrm{Fbxw} 7}$ [17]. Mammals express three alternatively spliced Fbxw7 isoforms (Fbxw7 $\alpha$, Fbxw7 $\beta$ and Fbxw7 $\gamma$ ) that are localized in the nucleus, cytoplasm and nucleolus, respectively [17]. Fbxw7 contains an F-box domain of $\sim 40$ amino acids (which interacts directly with Skp1 to recruit ubiquitin-conjugating enzymes) and eight WD40 repeats (which are required for its association with substrates) $[18,19]$. Substrates bind to Fbxw7 through a conserved phosphodegron (CPD), ФхФФФ(T/S)PPx(T/ $\mathrm{S} / \mathrm{E} / \mathrm{D})$, where $\Phi$ represents hydrophobic residues, and $\mathrm{T} / \mathrm{S}$ is phosphoserine or phosphothreonine [17]. Many studies from different groups have identified a growing list of specific Fbxw7 substrates, such as Aurora A, Cyclin E, c-Myc, c-Jun, c-Myb, Hypoxia-inducible factor- $1 \alpha$, Krüppel-like factor 5, Myeloid cell leukemia-1 (Mcl-1), mammalian target of rapamycin, Neurofibromatosis type 1, Notch, Nuclear factor E2-related factor 1, JUNB, Sterol regulatory element-binding proteins, Mediator 13, Krüppel-like factor 2, NF-кB2 and Granulocyte colony stimulating factor receptor (G-CSFR) [20]. Fbxw7 has been characterized as a general tumor suppressor in human cancer, and reduced Fbxw7 expression is often observed in multiple human cancers, including breast cancer, colorectal cancer, gastric cancer, prostate cancer, pancreatic cancer and hepatocellular carcinoma [17]. Moreover, emerging evidence has shown that Fbxw7 controls stem cell selfrenewal, cell fate decisions, survival, and multipotency in numerous tissues, including the hematopoietic [21] and nervous systems [22, 23], liver [24, 25], adipose tissue [26], endothelium [27], intestine [28], lung [29] and pancreas [30]. Because of the important role of Fbxw7 in various physiological and pathological processes, novel Fbxw7 substrates and biological functions of Fbxw7mediated protein turnover are of great interest.

In this study, we revealed that SOX10 is an unstable protein, and its stability is controlled by the ubiquitinproteasome proteolytic pathway. Further studies identified Fbxw $7 \alpha$ as a potential E3 ubiquitin ligase responsible for SOX10 turnover. Fbxw $7 \alpha$ bound to and facilitated the ubiquitination-mediated degradation of SOX10 through phosphodegron. This process is promoted by glycogen synthase kinase $3 \beta$ (GSK3 $\beta$ )-mediated phosphorylation of SOX10 at the CPD motif. More importantly, we found that Fbxw $7 \alpha$ suppresses melanoma cell migration by promoting SOX10 proteolysis. These findings help us to understand the post-translational regulatory mechanism of SOX10 and the underlying clinical significance of the Fbxw $7 \alpha-S O X 10$ axis in melanoma.

\section{RESULTS}

\section{SOX10 is an unstable protein}

To determine whether the SOX10 protein is stable, we assessed the half-life of SOX10 in melanoma cells using the cycloheximide ( $\mathrm{CHX}$ ) chase assay. Aurora-a, a validated unstable protein [31], was used as a positive control. As shown in Figure 1, the SOX10 protein level decreased steadily following protein synthesis inhibition by CHX treatment. The half-life of SOX10 was approximately $4 \mathrm{~h}$. In addition, proteasome inhibitor MG132 treatment induced SOX10 accumulation, suggesting that SOX10 degradation was mediated by ubiquitination.

\section{SOX10 interacts with Fbxw7a}

To explore the molecular mechanisms of SOX10 degradation, we sought to identify the E3 ubiquitin ligase responsible for this degradation. Analysis of the amino acid sequence of SOX10 revealed a potential conserved CPD identified in numerous Fbxw7 substrates located between amino acids 235 and 244 of SOX10 (Figure 2A). Considering that SOX10 is a transcription factor [32] which is usually localized in nucleus, we examined the possibility that SOX10 is a potential substrate of Fbxw $7 \alpha$, the only Fbxw7 isoform localizing in nucleus. Firstly, we tested whether SOX10 interacted with Fbxw7 $\alpha$ using coimmunoprecipitation (co-IP). HA-tagged SOX10 was cotransfected with or without Myc-tagged Fbxw7 $\alpha$ into 293T cells, and reciprocal co-IP using anti-Myc or anti-HA was performed. As shown in Figure 2B and 2C, the complex containing these two proteins was obviously detected in the cell lysates. Furthermore, the co-localization of Fbxw $7 \alpha$ and SOX10 was examined by co-transfected of EGFP-Fbxw7a and dsRed-SOX10 into Hela cells. 


\section{B16F10}
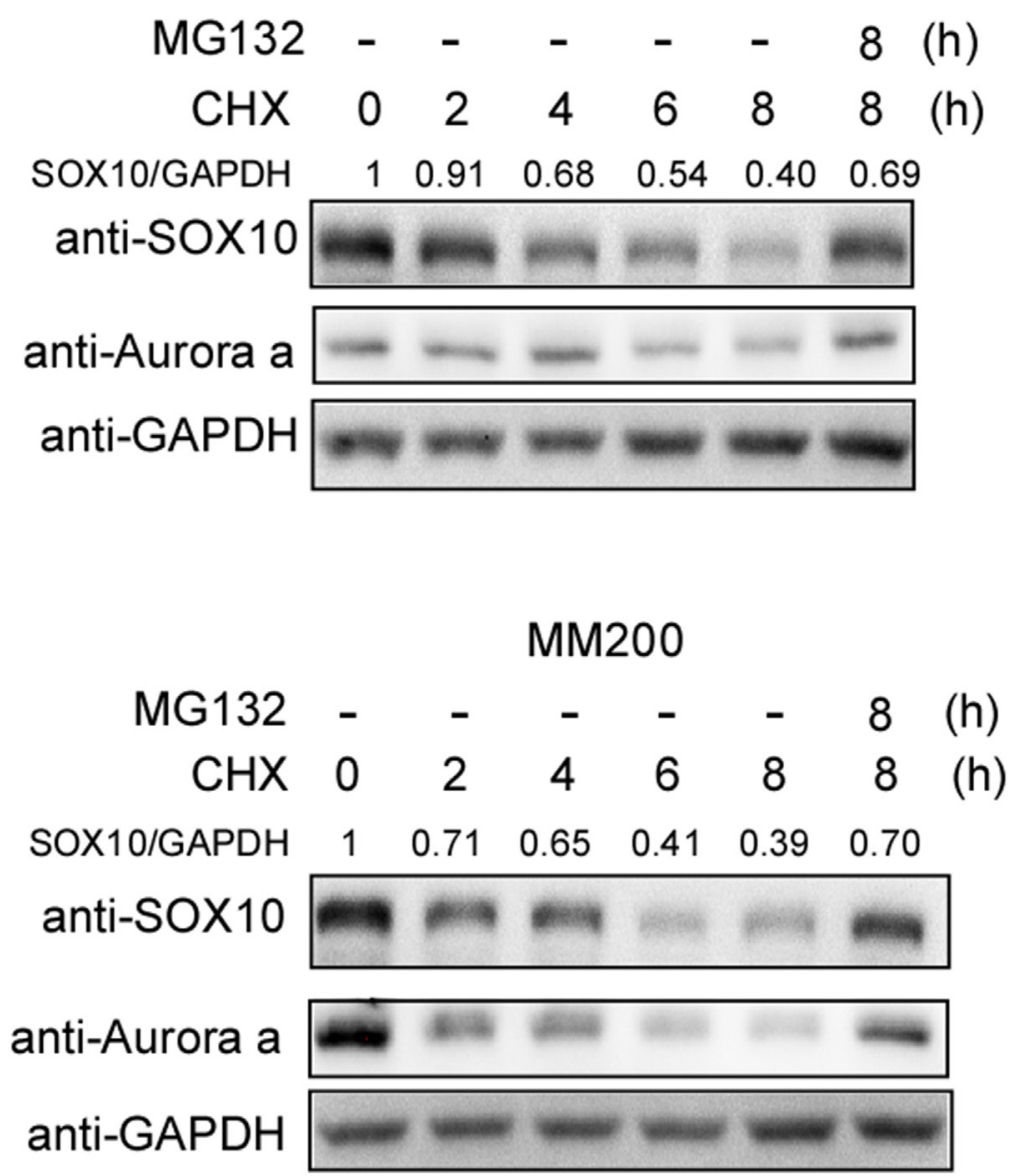

Figure 1: SOX10 is an unstable protein in melanoma cells. B16F10 (upper panel) and MM200 (bottom panel) cells were treated with $20 \mu \mathrm{g} / \mathrm{ml}$ cycloheximide (CHX) and $10 \mu \mathrm{M}$ MG132 for the indicated times before harvest. The cells were then analyzed by Western blotting with the indicated antibodies $(n=3)$.

As shown Figure 2D, Fbxw7 $\alpha$ and SOX10 were colocalized in nucleus, and MG132 treatment increased their level in nucleus. We next investigated the crucial domains responsible for their interaction. Mutation of the CPD motif (Figure 2E) abrogated the interaction between SOX10 and Fbxw7 $\alpha$ (Figure 2G), indicating that the CPD motif was essential for the recognition of SOX10 by Fbxw $7 \alpha$. In addition, deletion of the WD40 domain but not F-box (Figure 2F) abrogated the interaction between Fbxw $7 \alpha$ and SOX10 (Figure $2 \mathrm{H}$ ), indicating that Fbxw $7 \alpha$ binds to SOX10 through its WD40 domain.

\section{Fbxw7 $\alpha$ targets SOX10 for ubiquitination}

Fbxw $7 \alpha$ is a component of E3 ubiquitin ligase that promotes the degradation of target proteins through ubiquitination. Thus, we used an in vivo ubiquitination assay to test whether Fbxw $7 \alpha$ promotes SOX10 ubiquitination. 293T cells transfected with Myc-SOX10 and HA-ubiquitin in the absence or presence of FlagFbxw $7 \alpha$ were treated with MG132 for $6 \mathrm{~h}$ to stabilize the ubiquitinated proteins before lysis. In the absence of ectopic Fbxw7a, SOX10 was weakly ubiquitinated, whereas cotransfection of Fbxw $7 \alpha$ increased the ubiquitinated SOX10 level (Figure 3A). Moreover, deletion of either the F-box or WD40 domain abolished Fbxw $7 \alpha$-induced SOX10 ubiquitination (Figure 3B). These results indicate that $F b x w 7 \alpha$ facilitates the ubiquitination of SOX10.

\section{Fbxw7 $\alpha$ facilitates the degradation of SOX10}

Based on the observation that Fbxw $7 \alpha$ targets SOX10 for ubiquitination, we detected whether Fbxw $7 \alpha$ promoted SOX10 turnover. HA-SOX10 was co-transfected with different amounts of Myc-Fbxw $7 \alpha$ into $293 \mathrm{~T}$ cells. Skp2, another F-box containing SCF E3 ubiquitin ligase, was used as a control [33]. Indeed, 


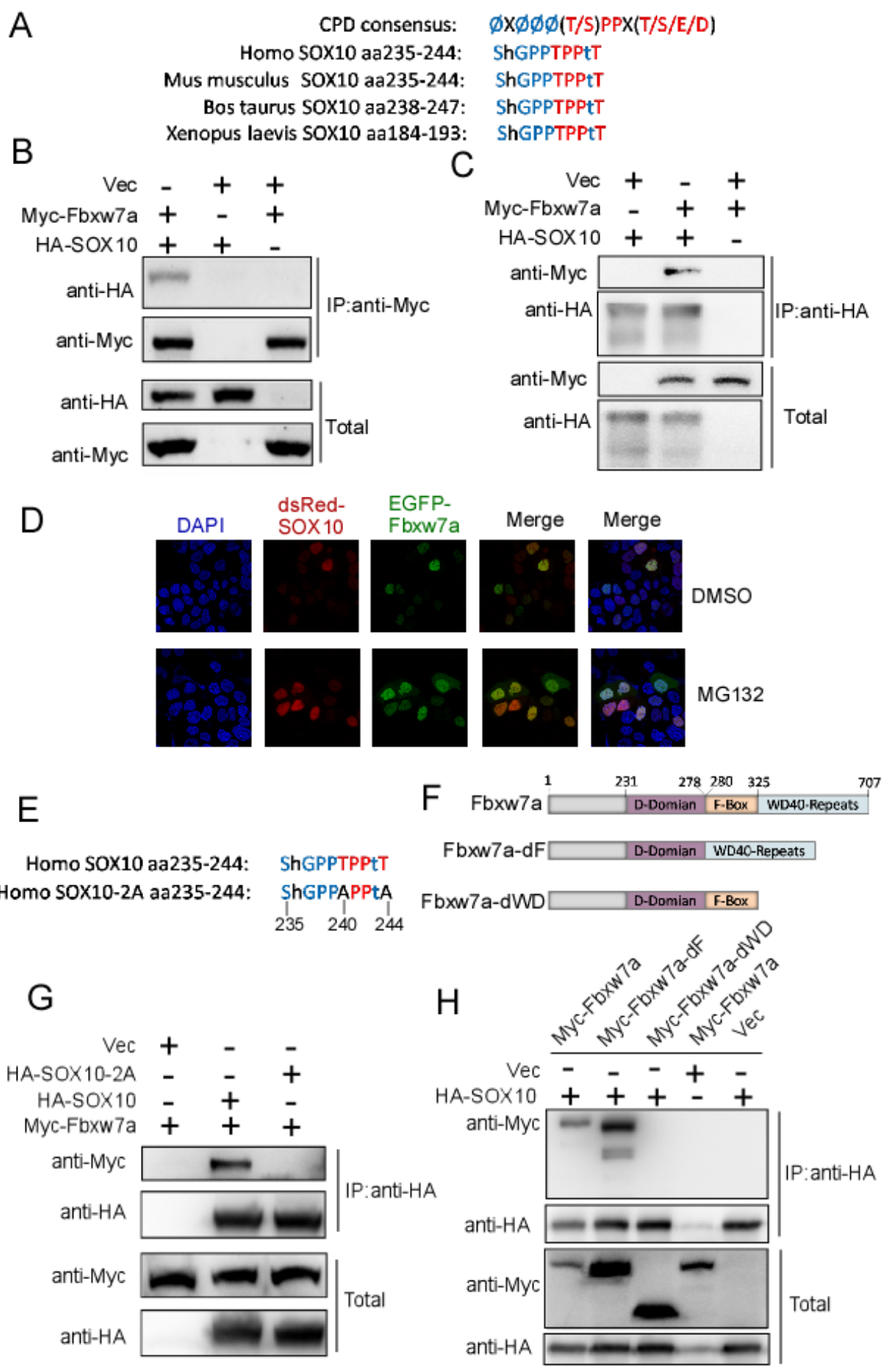

Figure 2: SOX10 is a potential substrate of Fbxw7a. A. Schematic illustration of the potential CPD sequence in SOX10. B. and C. SOX10 interacts with SOX10. $293 \mathrm{~T}$ cells transfected with the indicated plasmids for $24 \mathrm{~h}$ were lysed. Immunoprecipitation (IP) using anti-HA (B) or anti-Myc (C) agarose and Western blotting with the indicated antibody were performed $(n=3)$. D. Co-localization of Fbxw $7 \alpha$ and SOX10 in Hela cells. Hela cells cotransfected with EGFP-Fbxw $7 \alpha$ and dsRed-SOX10 for $24 \mathrm{~h}$ were fixed and dyed with DAPI. Then the Co-localization of Fbxw $7 \alpha$ and SOX10 was observed in the confocal microscope. E, F. Schematic illustration of the SOX10-2A mutant (E) and Fbxw $7 \alpha$ truncation (F). G. Mutation of the SOX10 CPD sequence abolished the interaction of SOX10 with Fbxw7 $\alpha$. 293T cells transfected with the indicated plasmids for $24 \mathrm{~h}$, and the formation of an immunoprecipitated complex was detected as described in Figure 2B $(n=3)$. H. Fbxw $7 \alpha$ interacts with SOX10 and this interaction is dependent on the WD40 domain. 293T cells were transfected with the indicated plasmids for $24 \mathrm{~h}$, and the formation of an immunoprecipitated complex was detected as described in Figure $2 \mathrm{~B}(n=3)$. 
A

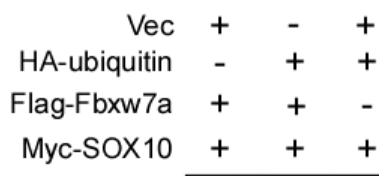

anti-Myc

anti-Flag
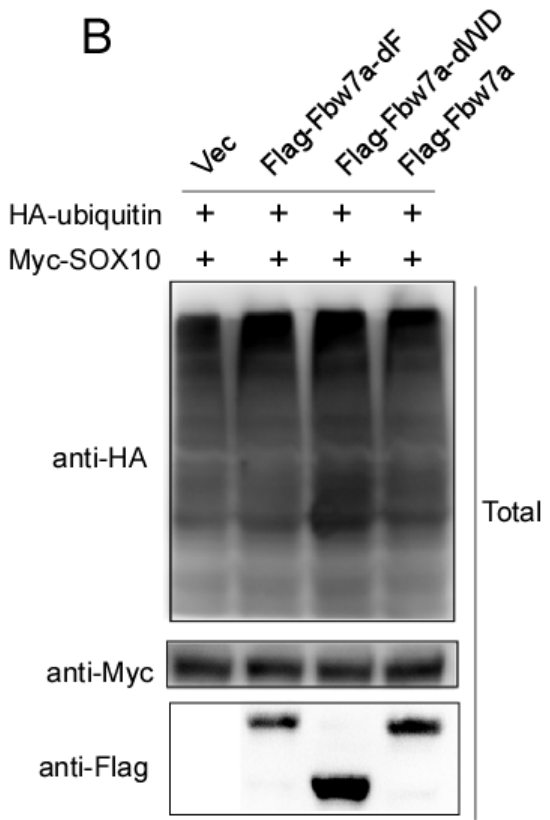
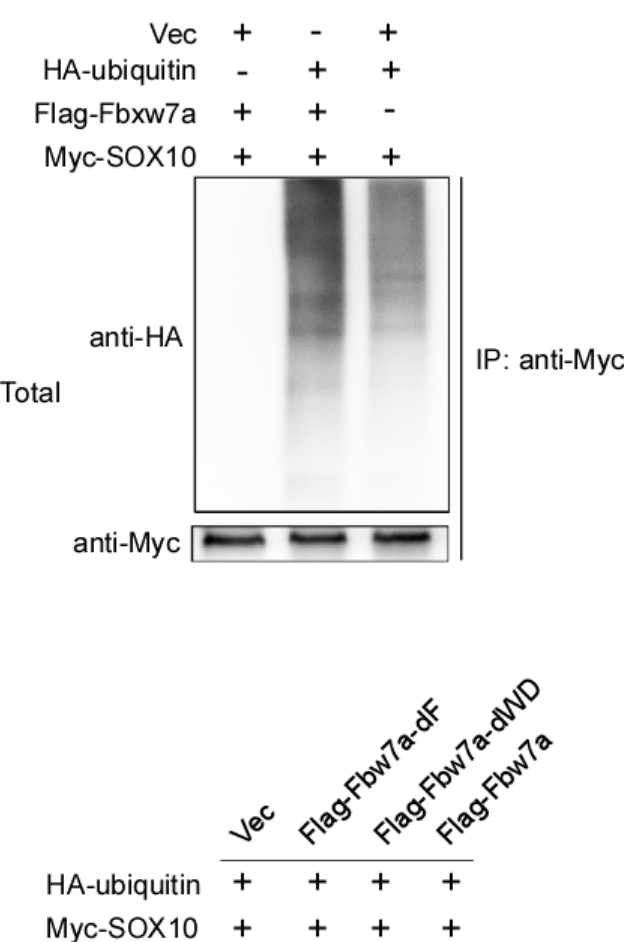

Myc-SOX10 $+\quad+\quad+$

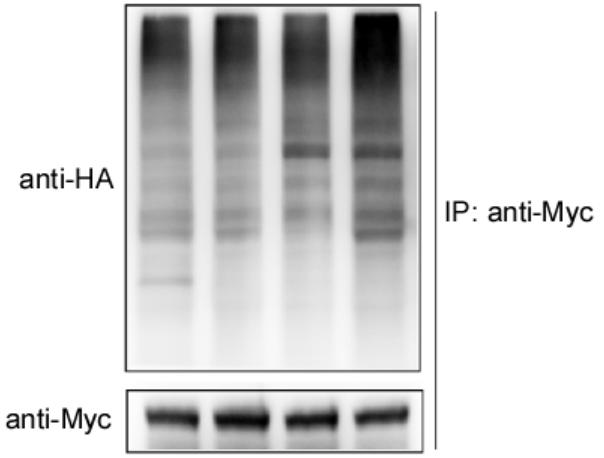

Figure 3: Fbxw7 $\alpha$ mediated SOX10 ubiquitination. A. $293 \mathrm{~T}$ cells transfected with the indicated plasmids for $24 \mathrm{~h}$ were treated with $10 \mu \mathrm{M}$ MG-132 for $4 \mathrm{~h}$ before lysis. Immunoprecipitation (IP) using anti-Myc agarose and Western blotting with the indicated antibody were performed $(n=3)$. B. Deletion of either the F-box or the WD40 domain abrogates the ability of Fbxw $7 \alpha$ to mediate the ubiquitination of SOX10. $293 \mathrm{~T}$ cells transfected with the indicated plasmids were treated with $10 \mu \mathrm{M}$ MG-132 for $6 \mathrm{~h}$ before lysis. Analysis of the ubiquitination level of SOX10 was performed as described in Figure 3A $(n=3)$.

Fbxw $7 \alpha$ overexpression reduced SOX10 protein levels in a dose-dependent manner, whereas Myc-Skp2 overexpression did not affect SOX10 protein levels (Figure 4A). Moreover, ectopic expression of HAFbxw $7 \alpha$ notably reduced the half-life of SOX10 using the CHX chase assay (Figure 4B), whereas deletion of either the F-box or the WD40 domain abolished Fbxw $7 \alpha$-mediated SOX10 turnover (Figure 4C). Moreover, mutation of the CPD sequence of SOX10 (SOX10-2A) abrogated its degradation by Fbxw7 $\alpha$ (Figure 4D). Taken together, these results indicate that $\mathrm{Fbxw} 7 \alpha$ is the E3 ubiquitination ligase that mediates SOX10 degradation.

\section{GSK3ß is required for the Fbxw7 $\alpha$-mediated degradation of SOX10}

Phosphorylation of $\mathrm{T} / \mathrm{S}$ in the CPD motif of Fbxw $7 \alpha$ substrates is required for recognition by Fbxw $7 \alpha$ [34]. We sought to determine which phosphokinase is responsible for the phosphorylation of the SOX 10 CPD motif. Scansite software analysis revealed that SOX10 CPD is a potential GSK3 $\beta$ phosphorylation motif (Figure 5A). We next examined the interaction between GSK $3 \beta$ and SOX10 by co-IP. HA-SOX10 was co-transfected with or without Myc-GSK3 $\beta$ into 293 T cells, and SOX10 was immunoprecipitated using 
A

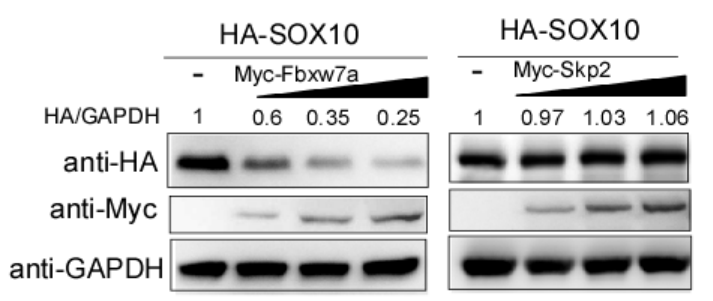

B

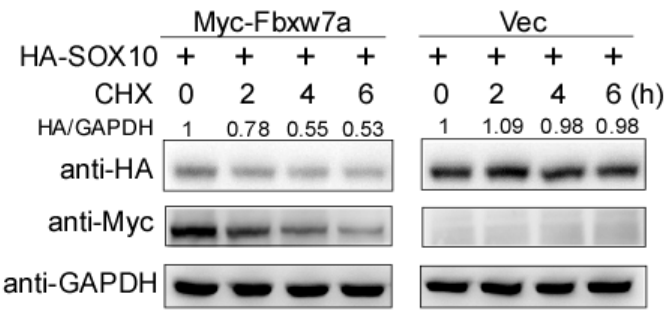

C
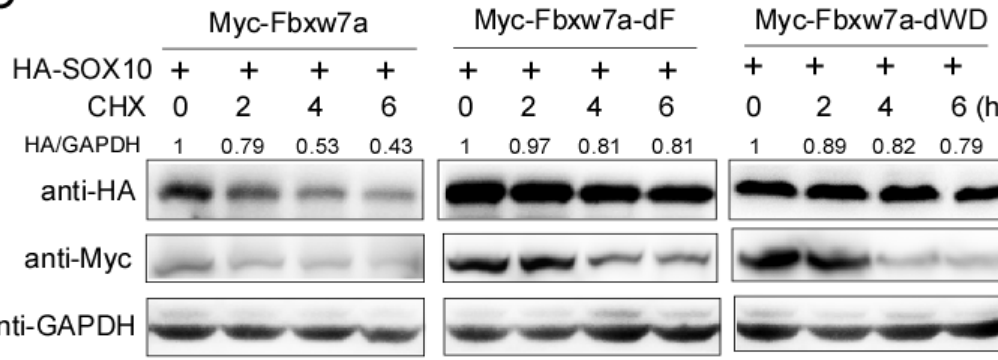

$0246(\mathrm{~h})$

$\begin{array}{llll}1 & 0.89 & 0.82 & 0.79\end{array}$

anti-GAPDH

D

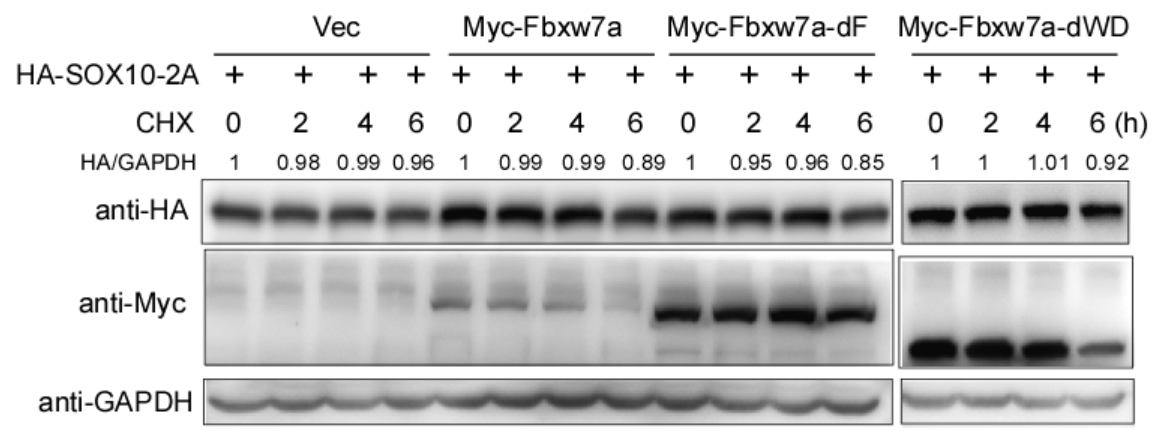

Figure 4: Fbxw7a mediated SOX10 degradation. A. Fbxw7 $\alpha$ transfection downregulates the SOX10 protein level in a dosedependent manner. $293 \mathrm{~T}$ cells were transiently transfected with HA-SOX10 and an increasing amount of Myc-Fbxw7 $\alpha$ or Myc-Skp2 for $24 \mathrm{~h}$ and were examined by Western blotting with the indicated antibodies $(n=3)$. B. Fbxw $7 \alpha$ transfection accelerates the degradation of SOX10. 293T cells transfected with the indicated plasmids for $24 \mathrm{~h}$ were treated with $20 \mu \mathrm{g} / \mathrm{ml} \mathrm{CHX}$ for the indicated times. The cells were then harvested and analyzed by Western blotting with the indicated antibodies $(n=3)$. C. Deletion of either F-box or WD40 domains abrogates the ability of Fbxw7 $\alpha$ to mediate the degradation of SOX10. $293 \mathrm{~T}$ cells transfected with the indicated plasmids for $24 \mathrm{~h}$ were treated with $20 \mu \mathrm{g} / \mathrm{ml} \mathrm{CHX}$ for the indicated times and were analyzed as described in Figure 4B $(n=3)$. D. Mutation of the CPD leads to the resistance of SOX10 to Fbxw7 $\alpha$-mediated degradation. 293T cells transfected with the indicated plasmids for $24 \mathrm{~h}$ were treated with $20 \mu \mathrm{g} / \mathrm{ml} \mathrm{CHX}$ for the indicated times and analyzed as described in Figure 4B $(n=3)$.

the anti-HA antibody. GSK3 $\beta$ was copurified with SOX10 only when they were cotransfected (Figure 5B). Furthermore, mutation of SOX10 CPD (SOX102A) abrogated their interaction, indicating that GSK3 $\beta$ interacts specifically with SOX10 and that this interaction depends on the potential GSK3 $\beta$ phosphorylation motif in CPD (Figure 5C). More importantly, in a in vitro kinase assay, we found that GSK3 $\beta$ directed phosphorylated SOX10, whereas mutation of SOX10 CPD (SOX10-2A) impaired this phosphorylation (Figure 5D).

We further tested whether GSK3 $\beta$ influenced SOX10 expression. HA-SOX10 was co-transfected with Myc-Fbxw7 $\alpha$ into $293 \mathrm{~T}$ cells with or without GSK $3 \beta$ knockdown, and the SOX10 protein level was monitored by Western blotting. The SOX10 protein level was downregulated upon co-transfecting with Fbxw $7 \alpha$, whereas silencing of GSK $3 \beta$ led to elevation of SOX10 levels compared with the siRNA control (Figure 5E). In addition, treatment with the GSK3 $\beta$ inhibitors $\mathrm{LiCl}$ or AR-A014418 reversed, at least in part, the Fbxw $7 \alpha$-mediated degradation of SOX10 and increased the half-life of SOX10 (Figure 5F). The half-life of $\beta$-Catenin, a well-known GSK3 $\beta$ substrate [35], was also increased upon $\mathrm{LiCl}$ or AR-A014418 treatment, indicated that these inhibitors worked well 

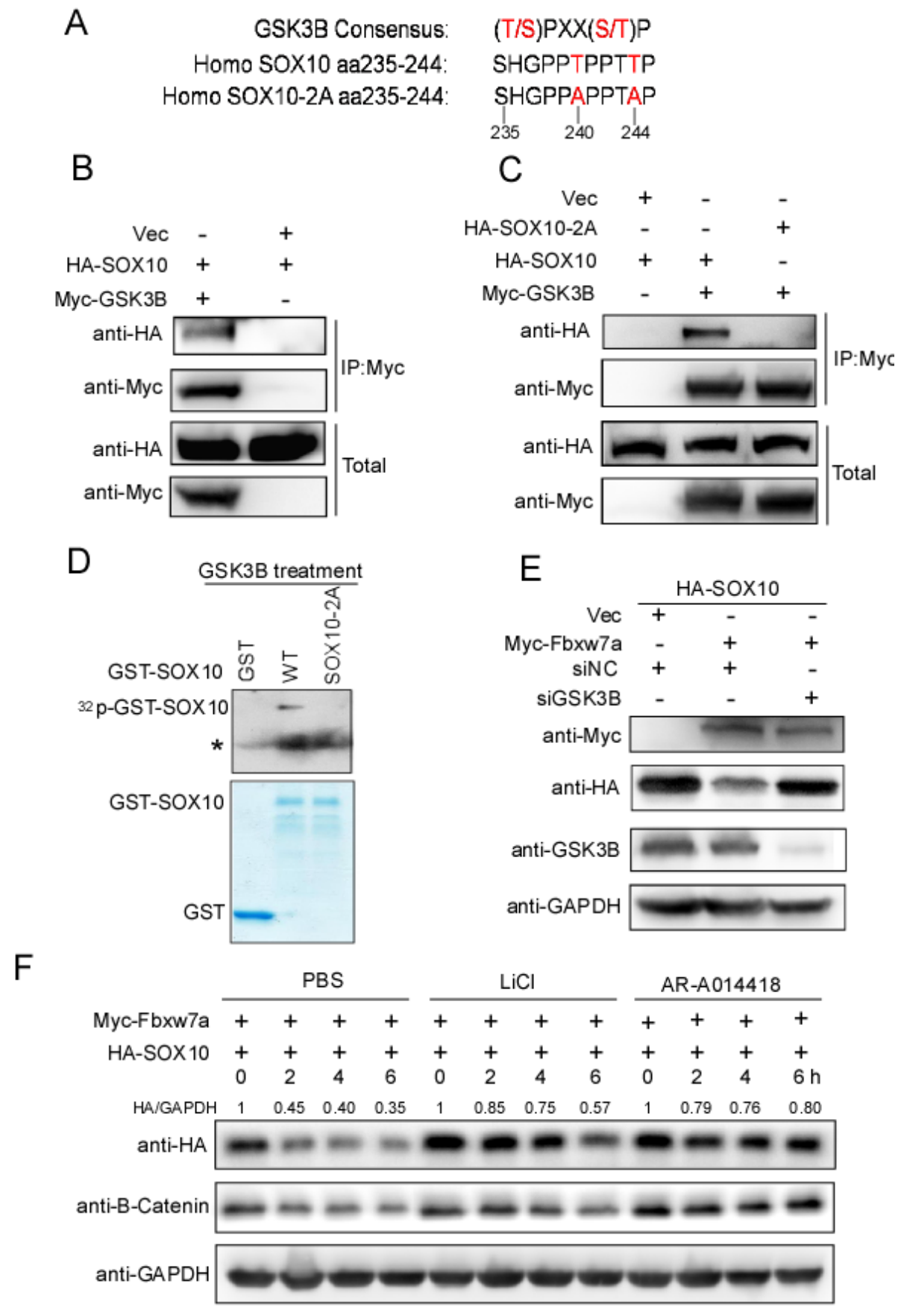

Figure 5: GSK3 $\beta$ is required for Fbxw7 $\alpha$-mediated SOX10 turnover. A. Schematic illustration of a GSK3 $\beta$ recognition consensus in the SOX10 CPD sequence. B. GSK3 $\beta$ interacts with SOX10. 293 T cells transfected with the indicated plasmids for $24 \mathrm{~h}$ were lysed. Immunoprecipitation using anti-Myc agarose and Western blotting with the indicated antibody were performed $(n=3)$. C. Mutation of the GSK3 $\beta$ recognition consensus abrogates the association of SOX10 with GSK3 $\beta$. 293T cells were transfected with the indicated plasmids for $24 \mathrm{~h}$, and the formation of an immunoprecipitated complex was detected as described in Figure 5B $(n=3)$. D. GSK3 $\beta$ phosphorylates SOX10 in vitro at CPD domain. GSK3 $\beta$ protein immunoprecipitated from Myc-GSK3 $\beta$ transfected $293 \mathrm{~T}$ cells was incubated with $5 \mu \mathrm{g}$ of the indicate GST or GST-SOX10 proteins in the presence of $\gamma$-32P-ATP. The kinase reaction products were resolved by SDS-PAGE and phosphorylation was detected by autoradiography $(n=3, *$ indicates non-specific band). E. Silencing of GSK3 $\beta$ abrogates, in part, Fbxw $7 \alpha$-mediated degradation of SOX10. 293T cells were transfected with the indicated plasmids, siRNAs were lysed, and the indicated protein levels were examined by Western blotting $(n=3)$. F. Treatment with the GSK3 $\beta$ inhibitor LiCl or AR-A014418 abolishes, in part, the Fbxw7 $\alpha$-mediated degradation of SOX10. 293T cells transfected with the indicated plasmids were treated with PBS, $20 \mathrm{mM} \mathrm{LiCl}$ or 20 $\mu \mathrm{M}$ AR-A014418 for $24 \mathrm{~h}$. The cells were then treated with $20 \mu \mathrm{g} / \mathrm{ml} \mathrm{CHX}$ for the indicated times before harvesting $(n=3)$. 
in the conditions(Figure 5F). Taken together, these results indicate that GSK $3 \beta$ could be the phosphokinase for the phosphorylation of the SOX10 CPD motif, and its kinase activity was required for $\mathrm{Fbxw} 7 \alpha$-mediated degradation of SOX10.

\section{Fbxw7 $\alpha$ regulates endogenous SOX10 in melanoma cells}

To further investigate the regulatory relationship between Fbxw $7 \alpha$ and SOX10, we first examined the endogenous interaction between Fbxw $7 \alpha$ and SOX10 in melanoma cells. A co-IP assay showed that the complex containing the two proteins was obviously detected in melanoma cells using either anti-Fbxw $7 \alpha$ or anti-SOX10 antibodies (Figure 6A). We next examined whether Fbxw $7 \alpha$ regulated the endogenous SOX10 level in melanoma cells. Fbxw $7 \alpha$ and SOX10 protein levels were detected by Western blotting in a panel of melanoma cells. As shown in Figure 6B, SOX10 was inversely correlated with the Fbxw $7 \alpha$ protein levels in melanoma cells. Moreover, Fbxw $7 \alpha$ overexpression in MM200 cells downregulated SOX10 expression (Figure 6C). MIA was reported to be a transcriptional target of SOX10 and responsible for SOX10 mediated melanoma migration [10]. We hence examined whether Fbxw $7 \alpha$ regulated MIA level. Indeed, MIA was also downregulated upon

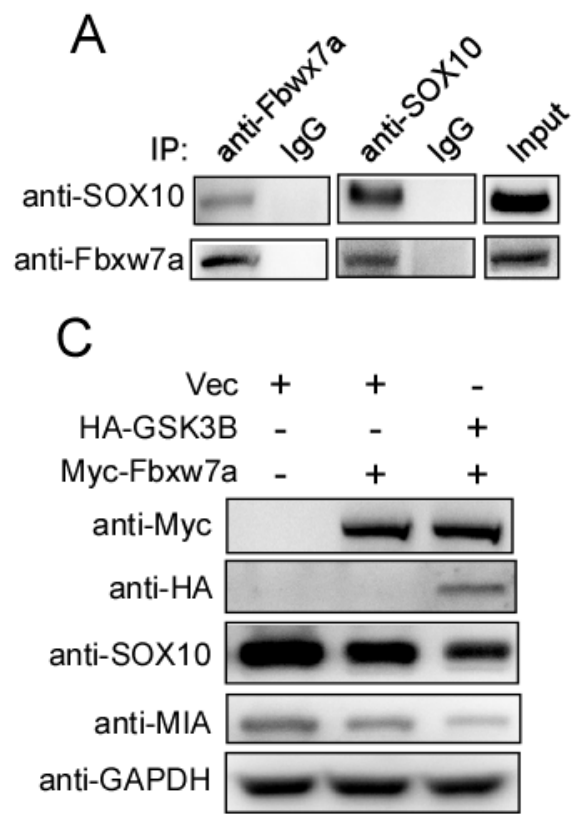

Fbxw7 $\alpha$ overexpression. Furthermore, co-transfection of GSK3 $\beta$ with Fbxw $7 \alpha$ further reduced the protein level of SOX10 compared with Fbxw $7 \alpha$ transfected alone (Figure 6C). By contrast, silencing of Fbxw7 $\alpha$ in SK-Mel$\mathrm{Bcl} 2$ cells increased the SOX10 and MIA protein levels (Figure 6D). Taken together, these results indicate that Fbxw $7 \alpha$ regulates the endogenous expression of SOX 10 in melanoma cells.

\section{Fbxw7 $\alpha$ suppresses melanoma migration through mediation of SOX10 turnover}

It has been reported that Fbxw $7 \alpha$ suppresses the migration of melanoma cells [36]. We investigated the role of SOX10 in Fbxw $7 \alpha$-mediated migratory inhibition of melanoma cells. SK-Mel-Bcl2 cells were transfected with Fbxw $7 \alpha$ siRNAs with or without SOX10 siRNA and were subjected to Transwell and wound-healing assays. The Transwell assay showed that Fbxw $7 \alpha$ siRNA transfection dramatically increased the filtered SK-Mel-Bcl2 cells, whereas co-transfection of SOX10 siRNA reduced the filtered cells similar to the negative control (Figure 7A). Consistently, the wound-healing assay showed that cotransfection of SOX10 siRNA reversed the elevation of the migratory ability of SK-Mel-Bcl 2 cells induced by Fbxw $7 \alpha$ silencing (Figure 7B). By contrast, ectopic expression of Fbxw $7 \alpha$ suppressed the migration of MM200 cells, whereas

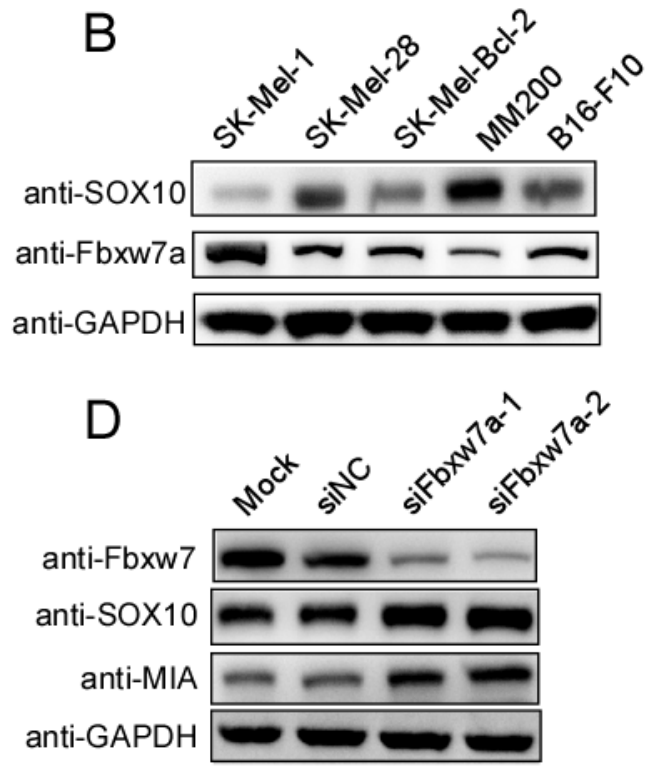

Figure 6: Fbxw7 $\alpha$ regulates the SOX10/MIA signaling pathway. A. Endogenous interaction between SOX10 and Fbxw7 $\alpha$ was detected in melanoma cells. MM200 cells were lysed and subjected to IP using IgG, anti-Fbxw7 $\alpha$, or anti-SOX10, as indicated, and then, the cells were analyzed by Western blotting $(n=3)$. B. The SOX10 protein level was inversely correlated with Fbxw7 $\alpha$. Various melanoma cell lines as indicated were lysed, and the protein levels of SOX10, Fbxw7 $\alpha$ and GAPDH were evaluated by Western blotting. C. Overexpression of Fbxw $7 \alpha$ and GSK3 $\beta$ downregulates the SOX10 and MIA protein levels $(n=3)$. MM200 cells were lysed, and the indicated protein levels were detected by Western blotting $(n=3)$. D. Silencing of Fbxw $7 \alpha$ upregulates the SOX10 and MIA protein levels. SK-Mel-Bcl 2 cells were lysed, and the indicated protein levels were detected by Western blotting $(n=3)$. 

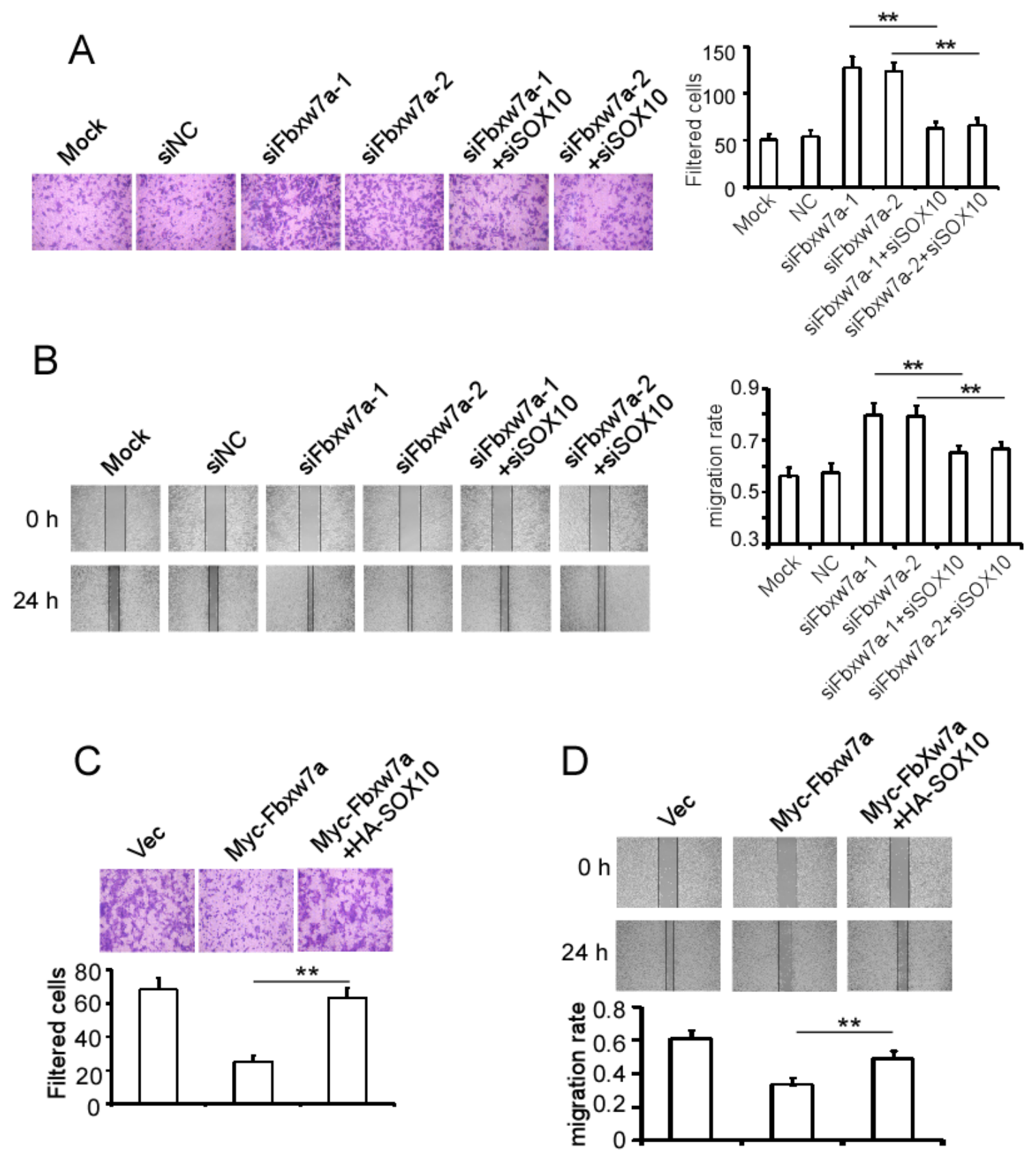

Figure 7: Fbxw7a suppresses cell migration through targeting SOX10 for degradation. A. and B. SK-Mel-Bcl2 cells were transfected with the indicated siRNAs for $48 \mathrm{~h}$, and their migratory ability was tested using a Transwell assay (A) and wound-healing assay (B). C. and D. MM200 cells were transfected with the indicated plasmids for $24 \mathrm{~h}$, and their migratory ability was tested using the Transwell assay (C) and wound-healing assay (D). The results are expressed as the mean $\pm \mathrm{SD} ; n=3, * * p<0.05$.

the combined transfection of SOX10 reversed Fbxw7 $\alpha$ exerted migration suppression effect using the Transwell assay (Figure 7C) and wound-healing assay (Figure 7D).

\section{DISCUSSION}

In this study, we provide evidence that SOX10 is a direct substrate of $\mathrm{SCF}^{\mathrm{Fbxw}}$. Fbxw7 $\alpha$ interacts with and promotes the ubiquitination-mediated degradation of SOX10 depending on its CPD motif. Moreover, the ubiquitination-dependent degradation of SOX10 by Fbxw7 $\alpha$ was enhanced by GSK-3 $\beta$. Furthermore, Fbxw7 $\alpha$ mediated degradation of SOX10 is pathologically relevant, given that SOX10 can reverse the Fbxw $7 \alpha$-mediated migration-suppression effect on melanoma cells.

Sox 10 expression is initiated in neural crest cells as they dissociate from the neural tube, and its expression is maintained during neural crest cell migration. Expression 
continues in the glial and melanocyte lineages, but Sox10 is turned off in many other neural crest cell derivatives [5, $32,37]$. Both the mRNA and protein level of SOX10 show restricted patterns of tissue-specific expression, suggesting that they undergo dominant regulation at the transcriptional level under physiological conditions. To explore whether SOX10 level was regulated posttranslational, we first accessed the stability of SOX10 using CHX chase assay. Our results indicate that SOX10 was an unstable protein. Besides, the observation that MG132 restored the SOX10 level suggested SOX10 might be degraded through a ubiquitination dependent manner. We hence search for the potential E3 ubiquitin ligase responsible for SOX10 turnover and identified Fbxw $7 \alpha$ was the E3 ligase mediated SOX10 degradation. Our results showed that overexpression of Fbxw $7 \alpha$ accelerated the SOX10 protein turnover using $\mathrm{CHX}$ chase assay. Interestingly, the Fbxw $7 \alpha$ protein levels also decrease with $\mathrm{CHX}$ treatment. This observation was consistent with previous report that Fbxw $7 \alpha$ was unstable due to autoubiquitylation [38]. SOX10 was found to be overexpressed in many cancers, including melanoma, schwannoma, neurofibroma, salivary gland tumors, astrocytoma and glioma [39]. The role of SOX10 in melanoma metastasis has been reported by several studies. Graf et al. examined a panel of melanoma cells and found that SOX10 mRNA amounts varied among melanoma cell lines and did not correlate with progression stage, whereas its protein level was associated with a more invasive or metastatic phenotype, indicating that the SOX10 protein level is regulated posttranslationally [10]. In this study, we found that Fbxw $7 \alpha$ promoted SOX10 degradation in melanoma cells. Moreover, the SOX10 protein level was inversely correlated with Fbxw7 $\alpha$ in a panel of melanoma cells. These results suggest a major role of the posttranslational regulation of SOX10 by Fbxw $7 \alpha$ in melanoma progression.

Fbxw $7 \alpha$ has been found to be involved in numerous cellular processes, including cell proliferation, apoptosis, cell cycle and differentiation [20]. Importantly, Fbxw7 $\alpha$ is considered a tumor suppressor protein primarily because Fbxw $7 \alpha$ targets multiple well-known oncoproteins, including Cyclin E, c-Myc, c-Jun, Mcl-1, and Notch-1 for ubiquitination-mediated destruction [34]. A recent report suggested that Fbxw $7 \alpha$ inhibits melanoma migration and may serve as a prognostic marker. The authors found that both Fbw 7 protein and mRNA expression was significantly reduced in nine melanoma cell lines compared with normal melanocytes. Moreover, silencing of Fbxw $7 \alpha$ results in a remarkable increase in cell migration and stress fiber formation of melanoma cells. However, the authors observed only a subtle change in Fbxw $7 \alpha$ substrates such as Myc and Cyclin E upon modulation of Fbxw $7 \alpha$ expression Fbxw7ain melanoma cells. These findings suggest that other Fbxw $7 \alpha$ substrates mediate the migration of melanoma cells [36]. In the present study, we determined that SOX10 is a novel target of Fbxw7 $\alpha$. Furthermore, a rescue experiment indicates that SOX10 could reverse Fbxw $7 \alpha$-exerted migration inhibition in melanoma cells. These results indicate that Fbxw $7 \alpha$ suppresses melanoma metastasis through targeting SOX10 degradation.

Fbxw $7 \alpha$ was reported to be frequently mutated in multiple tumors from the endometrium (15\%), large intestine $(9 \%)$, thyroid $(8 \%)$, hematopoietic and lymphoid tissue $(8 \%)$, pancreas $(3 \%)$, and others [40]. Mutation of Fbxw $7 \alpha$ in melanoma was also documented to be inactivated by somatic gene mutation $(\sim 8.1 \%, n=8)$ in metastatic melanomas by exome sequencing [41]. The inactivation of Fbxw $7 \alpha$ may lead to the accumulation of SOX10, which promotes melanoma migration.

In summary, we have shown that SOX10 protein stability was regulated by Fbxw $7 \alpha$-mediated ubiquitination degradation. We also show that Fbxw $7 \alpha$ suppressed the SOX10-mediated migration-promoting effect on melanoma cells. Given the frequent downregulation or inactivation of Fbxw $7 \alpha$ in melanoma, these findings may help us further understand the roles of the Fbxw $7 \alpha$ SOX10 axis in melanoma progression. Furthermore, the differentiation and development of melanocytes and glia may prove to be another useful model in understanding Fbxw $7 \alpha$-mediated degradation of SOX10, as the SOX10 protein level is attenuated in the differentiation and development of melanocytes and glia.

\section{MATERIALS AND METHODS}

\section{Cell lines}

Cells (293T, Hela, MM200, SK-Mel-Bc12, SKMel-1, SK-Mel-28, and B16-F10) were cultured in Dulbecco's Eagle's medium (Life Technologies, USA) supplemented with $10 \%$ fetal bovine serum (Biological Industries, Israel), $1 \mathrm{mM}$ glutamine, and 100 units $/ \mathrm{ml}$ each of penicillin and streptomycin.

\section{Plasmids}

Myc tag, HA tag or Flag tag expression cassettes were inserted into pcDNA3.1 to obtain the MycpcDNA3.1, HA-pcDNA3.1 and Flag-pcDNA3.1 vectors, respectively. Myc-Fbxw $7 \alpha$ and Flag-Fbxw7 $\alpha$ were obtained by inserting Fbxw $7 \alpha$ cDNA into the MycpcDNA3.1 or Flag-pcDNA3.1 vectors. SOX10 cDNA was cloned into the Myc-pcDNA3.1, HA-pcDNA3.1 and pGEX4T-2 plasmids to obtain Myc-SOX10, HASOX10 and GST-SOX10 recombinant vectors. HA$\mathrm{Ub}$ was obtained by cloning ubiquitin cDNA into the HA-pcDNA3.1 plasmid. HA-GSK3 $\beta$ and Myc-GSK3 $\beta$ [42] was a kind gift from Dr. Kang (Sun Yat-Sen University Cancer Center, Guangzhou China). Mutations were introduced using the Quik Change site-directed mutagenesis kit (Stratagene, USA), and all mutations were verified by DNA sequencing. 


\section{Antibodies}

The human anti-Fbxw7 $\alpha$ antibody was obtained from Abcam (ab12292). Human anti-SOX10 (sc-17342) anti-GSK3 $\beta$ (sc-53931) and anti-GAPDH (sc-166574) antibodies were obtained from Santa Cruz Biotechnology. Human anti-MIA (melanoma inhibitory activity) was purchased from Abnova (PAB27627) antibodies. AntiHA (\#3724), anti-Flag (\#14793) and anti-Myc (\#2278) were from Cell Signaling Technology. Bound primary antibodies were detected with either horseradish peroxidase-conjugated anti-mouse IgG HRP (SA00001-1, Proteintech, China) or horseradish peroxidase-conjugated anti-rabbit HRP (SA00001-2, Proteintech, China), and proteins were visualized by chemiluminescence.

\section{Transfection experiments}

Transfection was performed as described previously [43]. Briefly, cells seeded at $2.5 \times 10^{5}$ cells per well in a 6 -well plate or at $1 \times 10^{6}$ cells per $10-\mathrm{cm}$ plate were transfected with $2 \mu \mathrm{g}$ or $12 \mu \mathrm{g}$ of plasmid DNA, respectively, using Lipofectamine ${ }^{\mathrm{TM}} 2000$ (Life Technologies, USA).

\section{RNA interference}

Fbxw7 $\alpha$ siRNAs were purchased from Qiagen (siFbxw7 $\alpha-1$, Qiagen SI03089240) and Abnova (siFbxw7a-2, H00055294-R01). SOX10 siRNAs were purchased from Dharmacon (Smart pool, L-017192). GSK3 $\beta$ was designed according to previously validated oligonucleotides [42] and synthesized by GenePharma (Shanghai, China). Transfection was performed according to the manufacturer's instructions using Lipofectamine ${ }^{\mathrm{TM}}$ RNAiMAX transfection reagent (Life Technologies, USA) and $100 \mathrm{nM}$ siRNA. The transfected cells were incubated at $37^{\circ} \mathrm{C}$ for $48 \mathrm{~h}$ in complete medium and were harvested at the indicated time points.

\section{Western blotting and immunoprecipitation}

Western blotting and immunoprecipitation were performed as described previously [44]. Briefly, cells were lysed in RIPA buffer [50 mM Tris- $\mathrm{HCl}$ at $\mathrm{pH} 8.0,2 \mathrm{mM}$ DTT, $5 \mathrm{mM}$ EDTA, 0.5\% Nonidet P-40, $100 \mathrm{mM} \mathrm{NaCl}$, $1 \mathrm{mM}$ microcystin, $1 \mathrm{mM}$ sodium orthovanadate, $2 \mathrm{mM}$ phenylmethanesulfonyl fluoride (PMSF), $1 \times$ protease $\&$ phosphatase inhibitor cocktail (Thermo Scientific, \#1861281)], and clarified lysates were resolved by SDSPAGE and transferred to PVDF membranes for Western blotting using ECL detection reagents (Advansta, USA; R-03025-D25). Alternatively, clarified supernatants were first incubated with anti-Myc-agarose (Santa Cruz, SC40AC), anti-FLAG-agarose (Sigma, A2220), or antiHA-agarose (Sigma, A2095) for $2 \mathrm{~h}$ to overnight at $4^{\circ} \mathrm{C}$, and the precipitates were washed four times with RIPA buffer. To investigate the interaction between SOX10 and Fbxw $7 \alpha$ at the endogenous level, the clarified supernatants were first incubated with anti-Fbxw $7 \alpha$ or anti-SOX10 for $2 \mathrm{~h}$ at $4^{\circ} \mathrm{C}$. Protein A/G-agarose was then added and incubated for $2 \mathrm{~h}$ to overnight. Precipitates were washed four times with RIPA buffer and analyzed by Western blotting.

\section{Wound-healing and transwell assays}

These procedures were performed as described previously with small modification [45]. Briefly, cells were plated into 6-well-plates and cultured in complete medium supplemented with $20 \mu \mathrm{M}$ mitomycin $\mathrm{C}$ for $24 \mathrm{~h}$. The scraped, acellular area was created with a $200-\mu \mathrm{L}$ pipette tip. Then the cells were washed with PBS and cultured in DMEM medium with $0.5 \%$ FBS and $20 \mu \mathrm{M}$ mitomycin C. The spread of wound closure was observed after $24 \mathrm{~h}$ and imaged under a microscope. Migration assays were performed in modified Boyden chambers with $8-\mu \mathrm{m}$ pore filter inserts in 24-well plates (BD Transduction, USA). Briefly, $1 \times$ $10^{5}$ cells suspended in serum-free DMEM were added to the upper chamber of the insert in each well of a 24well culture plate. FBS was added to the lower chamber as a chemoattractant at a final concentration of $10 \%$. After $8 \mathrm{~h}$, the nonmigrated cells were gently removed with a cotton swab. The migrated cells in the lower part of the chamber were stained with crystal violet, air dried, and imaged.

\section{In vitro kinase assay}

GST-SOX10-WT, GST-SOX10-2A were produced in bacteria and purified and eluted as described previously [46]. GSK3 $\beta$ protein was enriched from Myc-GSK3 $\beta$ transfected 293T cells through immunoprecipitation using anti-Myc agarose. Kinase reactions were carried out in a reaction buffer consisting of $50 \mathrm{mM}$ Tris- $\mathrm{HCl}$, pH 7.4, $1 \mathrm{mM}$ DTT, $10 \mathrm{mM} \mathrm{MgCl}, 5 \mu \mathrm{Ci}[\gamma-32 \mathrm{P}]$ ATP, $500 \mu \mathrm{M}$ ATP, $2 \mu \mathrm{g}$ of soluble GST-SOX10 and MycGSK3 $\beta$ enriched agarose. Reactions were incubated at $30^{\circ} \mathrm{C}$ for $1 \mathrm{~h}$, then resolved by SDS-PAGE and detected by autoradiography.

\section{Statistical analyses}

Statistical analyses were performed using SPSS 16.0 software (SPSS Inc.). The values were expressed as the mean \pm standard deviation (SD) of three independent experiments, and the significance of differences between two groups was calculated using two-tailed Student's $t$-test. $P$-values less than 0.05 were considered significant. 


\section{ACKNOWLEDGMENTS AND FUNDING}

This work was supported by grants from the Natural Science Foundation of China (81560452 to XBL, 81201550 to JW, 81301732 to KH); Sun Yat-sen University Training Project (12ykpy32 to XBL) and Guangdong Natural Science Foundation (S2013040016404, to KH).

\section{COMPETING INTEREST}

The authors declare that they have no competing financial interests.

\section{REFERENCES}

1. Harris ML, Baxter LL, Loftus SK, Pavan WJ. Sox proteins in melanocyte development and melanoma. Pigment Cell Melanoma Res. 2010; 23:496-513.

2. Roh J, Cho EA, Seong I, Limb JK, Lee S, Han SJ, Kim J. Down-regulation of Sox10 with specific small interfering RNA promotes transdifferentiation of Schwannoma cells into myofibroblasts. Differentiation. 2006; 74:542-551.

3. Lee KE, Nam S, Cho EA, Seong I, Limb JK, Lee S, Kim J. Identification of direct regulatory targets of the transcription factor Sox 10 based on function and conservation. BMC Genomics. 2008; 9:408.

4. Wegner M. Secrets to a healthy Sox life: lessons for melanocytes. Pigment Cell Res. 2005; 18:74-85.

5. Herbarth B, Pingault V, Bondurand N, Kuhlbrodt K, Hermans-Borgmeyer I, Puliti A, Lemort N, Goossens M, Wegner M. Mutation of the Sry-related Sox10 gene in Dominant megacolon, a mouse model for human Hirschsprung disease. Proc Natl Acad Sci U S A. 1998; 95:5161-5165.

6. Britsch S, Goerich DE, Riethmacher D, Peirano RI, RossnerM, Nave KA, Birchmeier C, Wegner M. The transcription factor Sox10 is a key regulator of peripheral glial development. Genes Dev. 2001; 15:66-78.

7. Cronin JC, Wunderlich J, Loftus SK, Prickett TD, WeiX, Ridd K, Vemula S, Burrell AS, Agrawal NS, Lin JC, Banister CE, Buckhaults P, Rosenberg SA, Bastian BC, Pavan WJ, Samuels Y. Frequent mutations in the MITF pathway in melanoma. Pigment Cell Melanoma Res. 2009; $22: 435-444$.

8. Shakhova O, Zingg D, Schaefer SM, Hari L, Civenni G, Blunschi J, Claudinot S, Okoniewski M, Beermann F, Mihic-Probst D, Moch H, Wegner M, Dummer R, Barrandon Y, Cinelli P, Sommer L. Sox10 promotes the formation and maintenance of giant congenital naevi and melanoma. Nat Cell Biol. 2012; 14:882-890.

9. Cronin JC, Watkins-Chow DE, Incao A, Hasskamp JH, Schonewolf N, Aoude LG, Hayward NK, Bastian BC, Dummer R, Loftus SK, Pavan WJ. SOX10 ablation arrests cell cycle, induces senescence, and suppresses melanomagenesis. Cancer Res. 2013; 73:5709-5718.

10. Graf SA, Busch C, Bosserhoff AK, Besch R, Berking C. SOX10 promotes melanoma cell invasion by regulating melanoma inhibitory activity. J Invest Dermatol. 2014; 134:2212-2220.

11. Seong I, Min HJ, Lee JH, Yeo CY, Kang DM, Oh ES, Hwang ES, Kim J. Sox10 controls migration of B16F10 melanoma cells through multiple regulatory target genes. PLoS One. 2012; $7:$ e31477.

12. Antonellis A, Bennett WR, Menheniott TR, Prasad AB, Lee-Lin SQ, Green ED, Paisley D, Kelsh RN, Pavan WJ, Ward A. Deletion of long-range sequences at Sox10 compromises developmental expression in a mouse model of Waardenburg-Shah (WS4) syndrome. Hum Mol Genet. 2006; 15:259-271.

13. Antonellis A, Huynh JL, Lee-Lin SQ, Vinton RM, Renaud G, Loftus SK, Elliot G, Wolfsberg TG, Green ED, McCallion AS, Pavan WJ. Identification of neural crest and glial enhancers at the mouse Sox10 locus through transgenesis in zebrafish. PLoS Genet. 2008; 4:e1000174.

14. Deal KK, Cantrell VA, Chandler RL, Saunders TL, Mortlock DP, Southard-Smith EM. Distant regulatory elements in a Sox10-beta GEO BAC transgene are required for expression of Sox10 in the enteric nervous system and other neural crest-derived tissues. Dev Dyn. 2006; 235:1413-1432.

15. Zhu YT, Jia Y, Hu L, Qi C, Prasad MK, McCallion AS, Zhu YJ. Peroxisome-proliferator-activated receptor-binding protein (PBP) is essential for the growth of active Notch4immortalized mammary epithelial cells by activating SOX10 expression. Biochem J. 2010; 425:435-444.

16. Girard M, Goossens M. Sumoylation of the SOX10 transcription factor regulates its transcriptional activity. FEBS Lett. 2006; 580:1635-1641.

17. Welcker M, Clurman BE. FBW7 ubiquitin ligase: a tumour suppressor at the crossroads of cell division, growth and differentiation. Nat Rev Cancer. 2008; 8:83-93.

18. Hao B, Oehlmann S, Sowa ME, Harper JW, Pavletich NP. Structure of a Fbw7-Skp1-cyclin E complex: multisitephosphorylated substrate recognition by SCF ubiquitin ligases. Mol Cell. 2007; 26:131-143.

19. Orlicky S, Tang X, Willems A, Tyers M, Sicheri F. Structural basis for phosphodependent substrate selection and orientation by the SCFCdc4 ubiquitin ligase. Cell. 2003; 112:243-256.

20. Wang L, Ye X, Liu Y, Wei W, Wang Z. Aberrant regulation of FBW7 in cancer. Oncotarget. 2014; 5:2000-2015.

21. Iriuchishima H, Takubo $\mathrm{K}$, Matsuoka S, Onoyama I, Nakayama KI, Nojima Y, Suda T. Ex vivo maintenance of hematopoietic stem cells by quiescence induction through Fbxw7\&alpha; overexpression. Blood. 2011; 117:2373-2377. 
22. Hoeck JD, Jandke A, Blake SM, Nye E, Spencer-Dene B, Brandner S, Behrens A. Fbw7 controls neural stem cell differentiation and progenitor apoptosis via Notch and c-Jun. Nat Neurosci. 2010; 13:1365-1372.

23. Matsumoto A, Onoyama I, Sunabori T, Kageyama R, Okano H, Nakayama KI. Fbxw7-dependent degradation of Notch is required for control of "stemness" and neuronalglial differentiation in neural stem cells. J Biol Chem. 2011; 286:13754-13764.

24. Onoyama I, Suzuki A, Matsumoto A, Tomita K, Katagiri H, Oike Y, Nakayama K, Nakayama KI. Fbxw7 regulates lipid metabolism and cell fate decisions in the mouse liver. J Clin Invest. 2011; 121:342-354.

25. Yang H, Lu X, Liu Z, Chen L, Xu Y, Wang Y, Wei G, ChenY. FBXW7 suppresses epithelial-mesenchymal transition, stemness and metastatic potential of cholangiocarcinoma cells. Oncotarget. 2015; 6:6310-6325.

26. Bengoechea-Alonso MT, Ericsson J. The ubiquitin ligase Fbxw7 controls adipocyte differentiation by targeting C/ EBPalpha for degradation. Proc Natl Acad Sci U S A. 2010; 107:11817-11822.

27. Wang R, Wang Y, Liu N, Ren C, Jiang C, Zhang K, Yu S, Chen Y, Tang H, Deng Q, Fu C, Li R, Liu M, Pan W, Wang P. FBW7 regulates endothelial functions by targeting KLF2 for ubiquitination and degradation. Cell Res. 2013; 23:803-819.

28. Sancho R, Jandke A, Davis H, Diefenbacher ME, Tomlinson I, Behrens A. F-box and WD repeat domaincontaining 7 regulates intestinal cell lineage commitment and is a haploinsufficient tumor suppressor. Gastroenterology. 2010; 139:929-941.

29. Morra F, Luise C, Merolla F, Poser I, Visconti R, IlardiG, Paladino S, Inuzuka H, Guggino G, Monaco R, Colecchia D, Monaco G, Cerrato A, Chiariello M, Denning $\mathrm{K}$, Claudio PP, et al. FBXW7 and USP7 regulate CCDC6 turnover during the cell cycle and affect cancer drugs susceptibility in NSCLC. Oncotarget. 2015; .

30. Sancho R, Gruber R, Gu G, Behrens A. Loss of Fbw7 reprograms adult pancreatic ductal cells into alpha, delta, and beta cells. Cell Stem Cell. 2014; 15:139-153.

31. Shi Y, Solomon LR, Pereda-Lopez A, Giranda VL, Luo Y, Johnson EF, Shoemaker AR, Leverson J, Liu X. Ubiquitinspecific cysteine protease $2 \mathrm{a}$ (USP2a) regulates the stability of Aurora-A. J Biol Chem. 2011; 286:38960-38968.

32. Kuhlbrodt K, Herbarth B, Sock E, Hermans-Borgmeyer I, Wegner M. Sox10, a novel transcriptional modulator in glial cells. J Neurosci. 1998; 18:237-250.

33. Frescas D, Pagano M. Deregulated proteolysis by the F-box proteins SKP2 and beta-TrCP: tipping the scales of cancer. Nat Rev Cancer. 2008; 8:438-449.

34. Davis RJ, Welcker M, Clurman BE. Tumor suppression by the Fbw7 ubiquitin ligase: mechanisms and opportunities. Cancer Cell. 2014; 26:455-464.
35. McCubrey JA, Steelman LS, Bertrand FE, Davis NM, Sokolosky M, Abrams SL, Montalto G, D'Assoro AB, Libra M, Nicoletti F, Maestro R, Basecke J, Rakus D, Gizak A, Demidenko ZN, Cocco L, et al. GSK-3 as potential target for therapeutic intervention in cancer. Oncotarget. 2014; 5:2881-2911.

36. Cheng Y, Chen G, Martinka M, Ho V, Li G. Prognostic significance of Fbw7 in human melanoma and its role in cell migration. J Invest Dermatol. 2013; 133:1794-1802.

37. Pusch C, Hustert E, Pfeifer D, Sudbeck P, Kist R, Roe B, Wang Z, Balling R, Blin N, Scherer G. The SOX10/Sox10 gene from human and mouse: sequence, expression, and transactivation by the encoded HMG domain transcription factor. Hum Genet. 1998; 103:115-123.

38. Min SH, Lau AW, Lee TH, Inuzuka H, Wei S, Huang P, Shaik S, Lee DY, Finn G, Balastik M, Chen CH, Luo M, Tron AE, Decaprio JA, Zhou XZ, Wei W, et al. Negative regulation of the stability and tumor suppressor function of Fbw7 by the Pin1 prolyl isomerase. Mol Cell. 2012; 46:771-783.

39. Ordonez NG. Value of SOX10 immunostaining in tumor diagnosis. Adv Anat Pathol. 2013; 20:275-283.

40. Onoyama I, Tsunematsu R, Matsumoto A, Kimura T, de Alboran IM, Nakayama K, Nakayama KI. Conditional inactivation of Fbxw7 impairs cell-cycle exit during $\mathrm{T}$ cell differentiation and results in lymphomatogenesis. J Exp Med. 2007; 204:2875-2888.

41. Aydin IT, Melamed RD, Adams SJ, Castillo-Martin M, Demir A, Bryk D, Brunner G, Cordon-Cardo C, Osman I, Rabadan R, Celebi JT. FBXW7 mutations in melanoma and a new therapeutic paradigm. J Natl Cancer Inst. 2014; 106:dju107.

42. Tang QL, Xie XB, Wang J, Chen Q, Han AJ, Zou CY, Yin JQ, Liu DW, Liang Y, Zhao ZQ, Yong BC, Zhang RH, Feng QS, Deng WG, Zhu XF, Zhou BP, et al. Glycogen synthase kinase-3beta, NF-kappaB signaling, and tumorigenesis of human osteosarcoma. J Natl Cancer Inst. 2012; 104:749-763.

43. Gong C, Qu S, Lv XB, Liu B, Tan W, Nie Y, Su F, Liu Q, Yao H, Song E. BRMS1L suppresses breast cancer metastasis by inducing epigenetic silence of FZD10. Nat Commun. 2014; 5:5406.

44. Lv XB, Xie F, Hu K, Wu Y, Cao LL, Han X, Sang Y, Zeng YX, Kang T. Damaged DNA-binding protein 1 (DDB1) interacts with Cdh1 and modulates the function of APC/CCdh1. J Biol Chem. 2010; 285:18234-18240.

45. Lv XB, Jiao Y, Qing Y, Hu H, Cui X, Lin T, Song E, Yu F. miR-124 suppresses multiple steps of breast cancer metastasis by targeting a cohort of pro-metastatic genes in vitro. Chin J Cancer. 2011; 30:821-830.

46. Kang T, Wei Y, Honaker Y, Yamaguchi H, Appella E, Hung MC, Piwnica-Worms H. GSK-3 beta targets Cdc25A for ubiquitin-mediated proteolysis, and GSK-3 beta inactivation correlates with Cdc25A overproduction in human cancers. Cancer Cell. 2008; 13:36-47. 